\title{
Synthesis, Surface Activities and Anti-Bacterial Activity of (Copper and Nickel) Nanoparticles Stabilized by Cationic Thiol Polyurethane Surfactants
}

\author{
Ibrahim Abdelsalam Sabbah ${ }^{1,}$, , Mostafa Eid Hendawy ${ }^{1}$, Mohammed Fahmy Zaky ${ }^{2}$, \\ Nabel Abdelmonem Negm ${ }^{2}$ \\ ${ }^{1}$ Chemistry Department, Faculty of Science, Al-Azhar University, Cairo, Egypt \\ ${ }^{2}$ Petrochemicals Department, Egyptian Petroleum Research Institute, Cairo, Egypt
}

Email address:

ibrahimsabbah540@yahoo.com (I. A. Sabbah)

${ }^{*}$ Corresponding author

\section{To cite this article:}

Ibrahim Abdelsalam Sabbah, Mostafa Eid Hendawy, Mohammed Fahmy Zaky, Nabel Abdelmonem Negm. Synthesis, Surface Activities and Anti-Bacterial Activity of (Copper and Nickel) Nanoparticles Stabilized by Cationic Thiol Polyurethane Surfactants. Modern Chemistry. Vol. 6, No. 2, 2018, pp. 23-34. doi: 10.11648/j.mc.20180602.13

Received: June 12, 2018; Accepted: June 25, 2018; Published: July 27, 2018

\begin{abstract}
A series of cationic polyurethane surfactant [PQ14, PQ16 and PQ18] were synthesized by the reaction of alkyl bromoacetate (namely: tetradecyl-, hexadecyl- and octadecyl bromoacetate) as quaternizing agents and modified polyurethane contains tertiary amine species. Modified polyurethane was prepared by the reaction of toluene diisocyanate (TDI) and Triethanol amine mono mercaptoacetate. Grinding method is used to synthesize copper and nickel nanoparticles which stabilized by Cationic Thiol polyurethane surfactants. The chemical structures of the prepared surfactants were confirmed using elemental analysis, FTIR, UV and ${ }^{1}$ H-NMR spectroscopy. The molecular weight measurements of the prepared polymers showed that the segments of each polymer contain average 10 units of the urethane-Triethanol amine mercaptoacetate. The surface activities of the prepared surfactants including: surface tension $(\gamma)$, effectiveness $\left(\pi_{\mathrm{cmc}}\right)$, concentration at micelle formation $(\mathrm{CMC})$, efficiency $\left(\mathrm{Pc}_{20}\right)$, maximum concentration at the interface $\left(\Gamma_{\max }\right)$, average area occupied by each surfactant molecule at the interface at equilibrium $\left(\mathrm{A}_{\min }\right)$ of surfactants solutions were established at $25^{\circ} \mathrm{C}$. The surface tension and the critical micelle concentration values of the prepared surfactants were gradually decreased by the gradual increase of their alkyl chain length. Antimicrobial activity of the synthesized cationic surfactants and their nanostructure with copper and nickel nanoparticles were evaluated against pathogenic bacteria and fungi. The antimicrobial activity showed the enhancement in the antimicrobial activity of the synthesized cationic surfactants in the nanostructures form.
\end{abstract}

Keywords: Cationic Surfactants, Micellization, Adsorption, Surface Properties, Polyurethane, Antimicrobial Activity

\section{Introduction}

Polyurethanes are classified as one of the important polymers which participated in numerous purposes in almost all fabrications of nowadays life. Polyurethanes are used in various and diverse uses such as: furniture, bedclothes, chairs and instrument panels for automobiles, shoes, thermo insulation, carpet backings, packaging, and coatings. The main raw materials for the production of polyurethanes are polyols, diisocyanates and propylene oxide. For the preparation of polyurethane polymers, two types of reactants are needed; bifunctional isocyanates compounds and active hydrogen compounds. Bifunctional isocyanates are used to produce long chain monolayer polymer systems. Trifunctional isocyanates e.g., tris (4-isocyanatophenyl) thiophosphate are used in production of network polyurethanes which have higher mechanical, thermal and chemical resistance properties. The most commercial isocyanates are toluene diisocyanate and diphenyl methane diisocyanate. Polyols are used as hydrogen donating compounds [1]. Polyurethane nanoparticles were synthesized using several techniques such as suspension-poly condensation [2], interfacial poly condensation combined to 
spontaneous emulsification [3], suspension poly addition [4], and dispersion in organic solvent and supercritical carbon dioxide $[5,6]$.

Surface active agents are chemical compounds characterized by lowering the surface tension of the distilled water when dissolved in it even at infinite molar amounts. As their high tendency to decrease the interfacial interaction between the different polar media, surface active agents are incorporated in several industrial application as additives, especially in the polymer production as additives during emulsion polymerization processes.

Generally, cationic surfactants have been widely used owing to their excellent antibacterial activity, but the conventional cationic surfactants have strong irritant properties [7]. The biological activity data showed that the cationic surfactants and their nanostructure with copper and nickel nanoparticles exhibit moderate to high efficacy against the tested microorganisms.

\section{Materials and Methods}

\subsection{Chemicals}

Tetradecanol, hexadecanol and octadecanol, toluene diisocyanate (TDI), mercaptoacetic acid, and Bromoacetic acid were purchased from Sigma-Aldrich (Germany) in a purity of $99.9 \%$. Copper Chloride and Nickel chloride were purchased from BDH, British. Triethanol amine, ethyl alcohol and paraffin oil were purchased from ADWIC (Egypt) in a purity of $99.8 \%$.

\subsection{Instrumentation}

Elemental analysis: Vario Elementar Analyzer; FTIR spectroscopy: Perkin Elmer Genesis Fourier Transformer FTIR measured at $4000-400\left(\mathrm{~cm}^{-1}\right)$ applying potassium bromide compressed thin pellet technique. The nuclear magnetic resonance spectra were measured by Varian NMR300, Mercury $300 \mathrm{MHz}$ spectrometers using $\mathrm{CDCl}_{3}$ as solvent and trimethyl silane (TMS) as a reference to determine the different chemical shifts $\delta(\mathrm{ppm})$; Ultra violet was done using Perkin-Elmer S52 spectrophotometer; Transmission Electron Microscope (TEM) was done using JEOL JEM-2000, Germany; surface and interfacial tension measurements were obtained using K6-Kruss tensiometer with platinum ring. GPC measurements were performed using GPC-7890A instrument equipped with DB-23 column, $60 \mathrm{~mm} \times 0.25 \mathrm{~mm}$, i.d. of $0.25 \mu \mathrm{m}$.

\subsection{Synthesis}

\subsubsection{Preparation of Triethanol Amine Mono Mercaptoacetate}

Triethanol amine $(0.1$ mole) and mercaptoacetic acid $(0.1$ mole) were charged in $250 \mathrm{~mL}$ round flask in presence of xylene $(75 \mathrm{~mL})$ as a solvent and $p$-toluene sulfonic acid $(0.1$ g) as a dehydrating agent. The completion of the reaction was monitored by obtaining 0.1 mole of $\mathrm{H}_{2} \mathrm{O}(1.8 \mathrm{~mL})$ [8]. At the end of the reaction, the solvent was removed by evaporated by the effect of evacuation, while $p$-toluene sulfonic acid was eliminated from the reaction medium by take out the obtained esters by dissolving in ether (diethyl ether). The evaporated solvent was recovered and purified to reuse. The unreacted and excess reactants were eliminated from the products by successive sanitization of the crude products to afford Triethanol amine mono mercaptoacetate in a yield of $96 \%$.

\subsubsection{Preparation of Thiol Polyurethane (P)}

Thiol polyurethane polymerization reaction was carried out in a suitable flat bottom glass reactor $(500 \mathrm{~mL})$ connected to a mechanical rotor, dropping funnel, thermometer and condenser. Inside the reaction vessel, a mixture of toluene diisocyanate (TDI, 0.1 mole) dissolved in methyl ethyl ketone $(50 \mathrm{~mL})$, triethanol amine mercaptoacetate $(0.2 \mathrm{~mole})$ and five drops of triethylene diamine dropped during $20 \mathrm{~min}$ was mixed [9]. The reaction medium was continuously mixed at $30^{\circ} \mathrm{C}$ for $30 \mathrm{~min}$ to obtain the pre-polymer. The ratio of isocyanates $(\mathrm{NCO})$ to reactive hydroxyl group $(\mathrm{OH})$ was reserved at 1:2 in polyurethane reaction polymerization. The prepared polymer was washed twice using appropriate amounts of methyl ethyl ketone and finally dried (yield $92 \%)$.

\subsubsection{Preparation of Fatty Esters Bromoacetate (Q14, Q16, and Q18)}

Fatty esters bromoacetate were prepared throughout reacting different fatty alcohols $(0.1$ mole $)$ namely: octanol, decanol, dodecanol, tetradecanol, hexadecanol and octadecanol $\left(\mathrm{C}_{8}-\mathrm{C}_{18}\right)$ and Bromoacetic acid $(0.1 \mathrm{~mole})$ in the presence of xylene $(100 \mathrm{~mL})$ as a solvent and $p$-toluene sulphonic acid $(0.01 \mathrm{wt} \%)$ as dehydrating agent under heating and stirring conditions until the expected amount of water $(1.8 \mathrm{~mL})$ is produced. At the end of the reaction, xylene was stripped off using reduced pressure; $p$-toluene sulphonic acid was eliminated by extracting the product from diethyl ether and the solvent was removed [10] to afford the different fatty esters bromoacetate (yield 95-98\%).

\subsubsection{Preparation of Cationic Thiol Polyurethane Surfactants (PQ14, PQ16 and PQ18)}

Cationic Thiol polyurethane surfactants (PQ14, PQ16 and PQ18) were prepared by refluxing equimolar amounts of thiol polyurethane (P) and tetradecyl, hexadecyl, octadecyl individually in a suitable amount of dimethyl formamide (DMF) for $20 \mathrm{~h}$. The produced compounds were filtered off, washed by excess DMF, and dried under reduced pressure at $50^{\circ} \mathrm{C}$ to afford yellow to brown viscous liquids designated as: PQ14, PQ16 and PQ18 (yield 82-89\%) [11, 12] (Figure 1). 


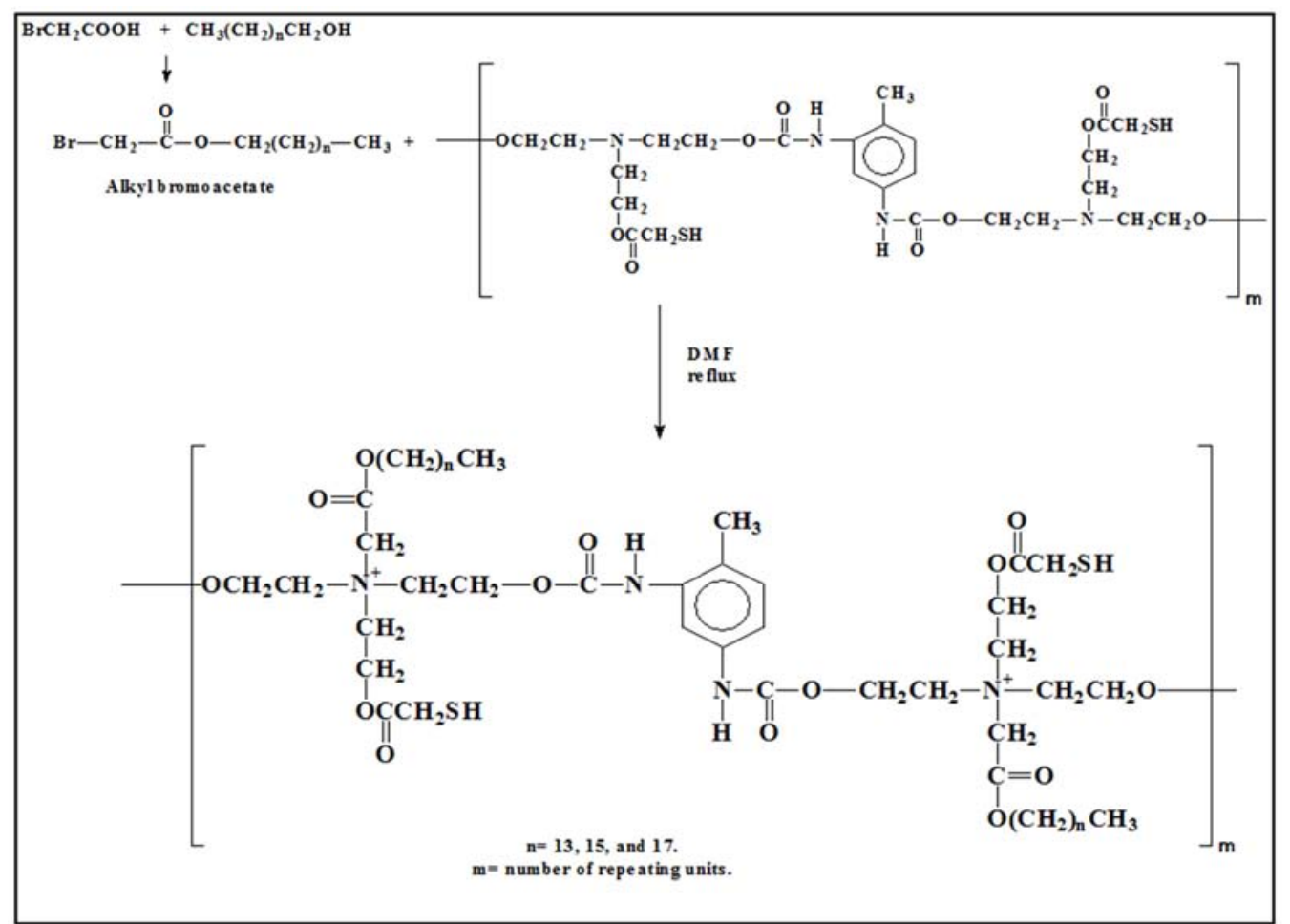

Figure 1. Preparation of the cationic Thiol polyurethane surfactants.

\subsubsection{Synthesis of Nano Cationic Thiol Polyurethane Tetrahalo Metallate PQ-M NPs}

By grinding (0.1 mole) of Copper chloride dihydrate and Nickel chloride hexahydrate with ( 0.2 mole) of cationic Thiol polyurethane surfactants in the mortar until all components mixed well. After then ethanoic solution of the previous mixture was refluxed under magnetic stirring for about 2 hours to produce tetra halo metallate complexes and this indicate by change the color of mixture. The product was poured into a flat plate and dried in the hood, washed with alcohol twice and dried. The product is believed to have the structure in (Figure 2) [13, 14].

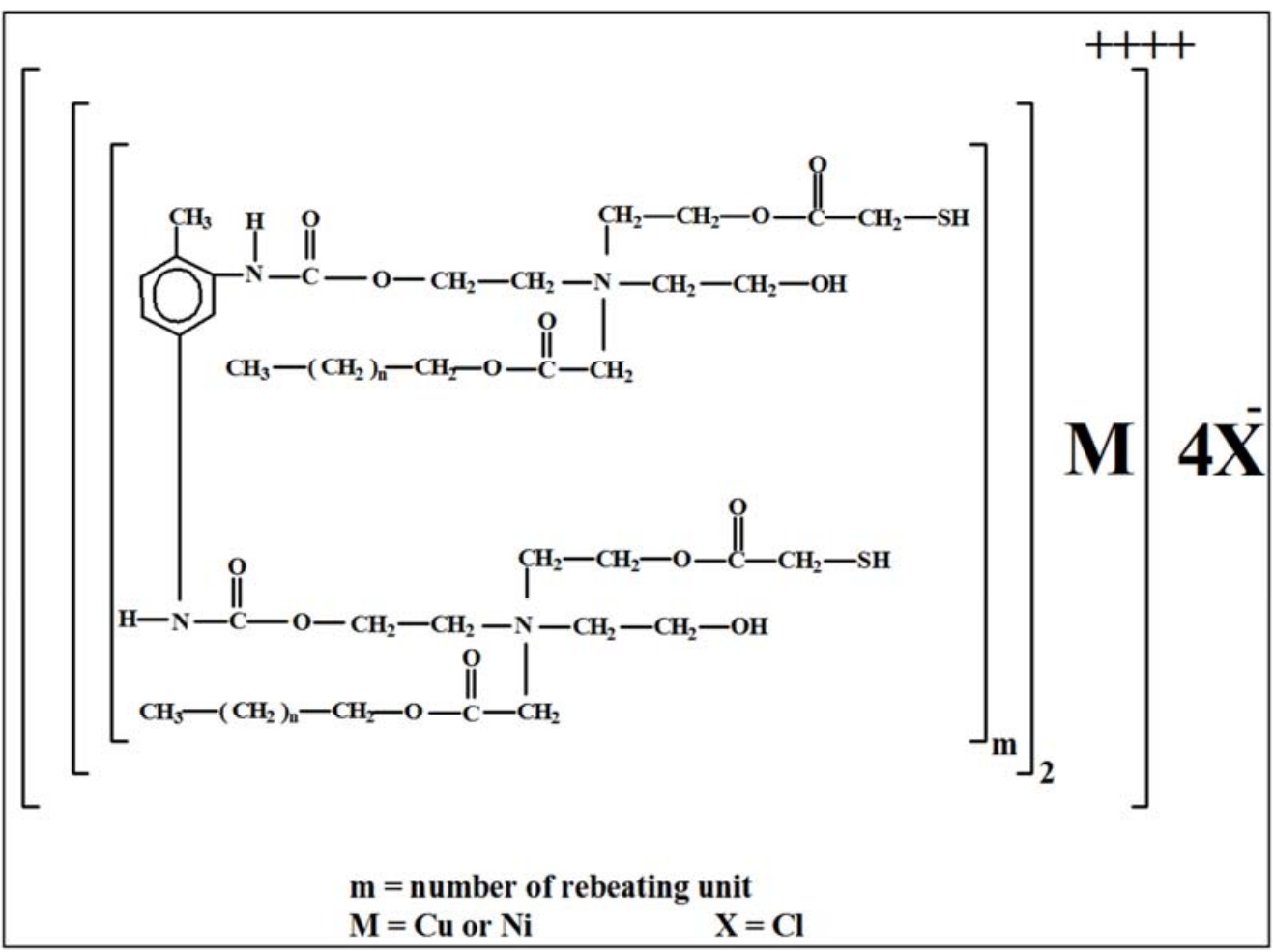

Figure 2. Synthesized Nano cationic Thiol polyurethane tetrahalo metallate PQ-M NPS. 


\subsection{Measurements}

\subsubsection{Surface Tension Measurements}

Surface tension measurements were carried out using DeNouy Kruss-K6 tensiometer with platinum ring. Freshly prepared aqueous solutions of the prepared cationic polyurethane surfactants (PQ14, PQ16 and $\mathrm{PQ}_{18}$ ) were used at a concentration range of $10^{-3}-10^{-7} \mathrm{M}$. Apparent surface tension values were measured at $25{ }^{\circ} \mathrm{C}$ in triplicate for each sample within 2 minutes interval between the readings and the average was considered [15]. The tensiometer was calibrated before each measurement using bi-distilled water at $25^{\circ} \mathrm{C}$.

\subsubsection{GPC Chromatography}

GPC Chromatographic analysis of the prepared surfactants were performed to determine their molecular weights using GPC-7890A instrument equipped with DB-23 column, 60 $\mathrm{mm} \times 0.25 \mathrm{~mm}$, i.d. of $0.25 \mu \mathrm{m}$, and water was used as a solvent, while polyethylene glycols of different molecular weights were used as references [16].

\section{Results and Discussion}

\subsection{Chemical Structure}

Figure 1 and Figure 2 represents the preparation of polyurethane cationic surfactants and their nano compounds.

The elemental analysis of the prepared cationic polyurethane surfactants (Table 1) showed the comparable values of the predicted and obtained ratios of the different elements in their chemical structure. The chemical structures of the prepared cationic polyurethane surfactants were confirmed using molecular weight measurements, elemental analysis, FTIR spectroscopy and ${ }^{1}$ H-NMR spectroscopy.

Table 1. Elemental analysis of the synthesized cationic Thiol polyurethane surfactants.

\begin{tabular}{|c|c|c|c|c|c|c|c|c|c|c|c|c|}
\hline \multirow{2}{*}{ Compound } & \multirow{2}{*}{$\begin{array}{l}\text { M.Wt, * } \\
\text { g/mole }\end{array}$} & \multirow{2}{*}{ Formula } & \multicolumn{2}{|l|}{$\mathrm{C} \%$} & \multicolumn{2}{|l|}{ H\% } & \multicolumn{2}{|l|}{$\mathbf{N \%}$} & \multicolumn{2}{|l|}{$\mathrm{S} \%$} & \multicolumn{2}{|l|}{$\mathrm{Br} \%$} \\
\hline & & & Calc. & Found & Calc. & Found & Calc. & Found & Calc. & Found & Calc. & Found \\
\hline PQ14 & 23200 & $\left(\mathrm{C}_{57} \mathrm{H}_{102} \mathrm{Br}_{2} \mathrm{~N}_{4} \mathrm{O}_{14} \mathrm{~S}_{2}\right)_{\mathrm{n}}$ & 52.04 & 52.00 & 7.74 & 7.76 & 4.76 & 4.73 & 5.44 & 5.41 & 13.60 & 13.56 \\
\hline PQ16 & 24100 & $\left(\mathrm{C}_{61} \mathrm{H}_{110} \mathrm{Br}_{2} \mathrm{~N}_{4} \mathrm{O}_{14} \mathrm{~S}_{2}\right)_{\mathrm{n}}$ & 53.57 & 53.54 & 8.03 & 8.05 & 4.54 & 4.51 & 5.19 & 5.17 & 12.99 & 12.96 \\
\hline PQ18 & 25000 & $\left(\mathrm{C}_{65} \mathrm{H}_{118} \mathrm{Br}_{2} \mathrm{~N}_{4} \mathrm{O}_{14} \mathrm{~S}_{2}\right)_{\mathrm{n}}$ & 54.97 & 54.93 & 8.31 & 8.29 & 4.35 & 4.32 & 4.97 & 4.95 & 12.44 & 12.39 \\
\hline
\end{tabular}

* Obtained molecular weight from GPC measurements, $\mathrm{n} \approx 18$.

\subsubsection{FTIR Spectroscopic Analysis}

The chemical structures of the prepared cationic surfactants and their intermediates were confirmed using FTIR spectroscopic analysis. FTIR spectra of triethanol amine mercaptoacetate showed the following absorption bands: broad absorption band centered at $3435 \mathrm{~cm}^{-1}$ corresponds to $-\mathrm{OH}$ stretching; weak absorption band at $2550 \mathrm{~cm}^{-1}$ corresponds to stretching of S-H group; absorption band at $2932 \mathrm{~cm}^{-1}$ attributed to symmetric stretching of C-H group; $1018 \mathrm{~cm}^{-1}$ corresponds to $\mathrm{C}-\mathrm{N}$ stretching group of aliphatic amine and absorption band at $1732 \mathrm{~cm}^{-1}$ corresponds to $\mathrm{C}=\mathrm{O}$ ester group.

Thiol polyurethane compound $(\mathrm{P})$ showed the following absorption bands: $1663 \mathrm{~cm}^{-1}$ corresponds to $\mathrm{C}=\mathrm{O}$ of urethane group; 1458 and $1462 \mathrm{~cm}^{-1}$ corresponds to $\mathrm{N}-\mathrm{H}$ of urethane group; $1508-1510 \mathrm{~cm}^{-1}$ described for the double bonds in the phenyl moiety $(\mathrm{C}=\mathrm{C})$ in toluene diisocyanate moiety (TDI).
FTIR spectra of alkyl bromoacetate esters represented the disappearance of the broad band at $3400 \mathrm{~cm}^{-1}$ of alcoholic hydroxyl groups of the reacted fatty alcohols, the appearance of new absorption bands at: $1736-1738 \mathrm{~cm}^{-1}$ corresponds to carbonyl ester indicates the ester (Q14, Q16 and Q18) formation; $1275-1277 \mathrm{~cm}^{-1}$ corresponds to ether linkages C-OC; $2920-2922 \mathrm{~cm}^{-1}$ and $2849-2850 \mathrm{~cm}^{1}$ corresponded to symmetric and asymmetric stretching of $\mathrm{C}-\mathrm{H}$ groups. The characteristic absorption band of $\mathrm{C}-\mathrm{Br}$ bond was appeared in the range of $663-667 \mathrm{~cm}^{-1}$. IR spectra of the prepared cationic polyurethane surfactants showed similar absorption bands to the absorption bands of triethanol amine mercaptoacetate, thiol polyurethane and alkyl bromoacetate esters. Furthermore, IR spectra recorded a disappearance of the absorption band at 660 $\mathrm{cm}^{-1}$ and the appearance of a new absorption band at $3040 \mathrm{~cm}^{-1}$ corresponded to $\mathrm{C}-\mathrm{N}^{+}$group (Figure 3 ).

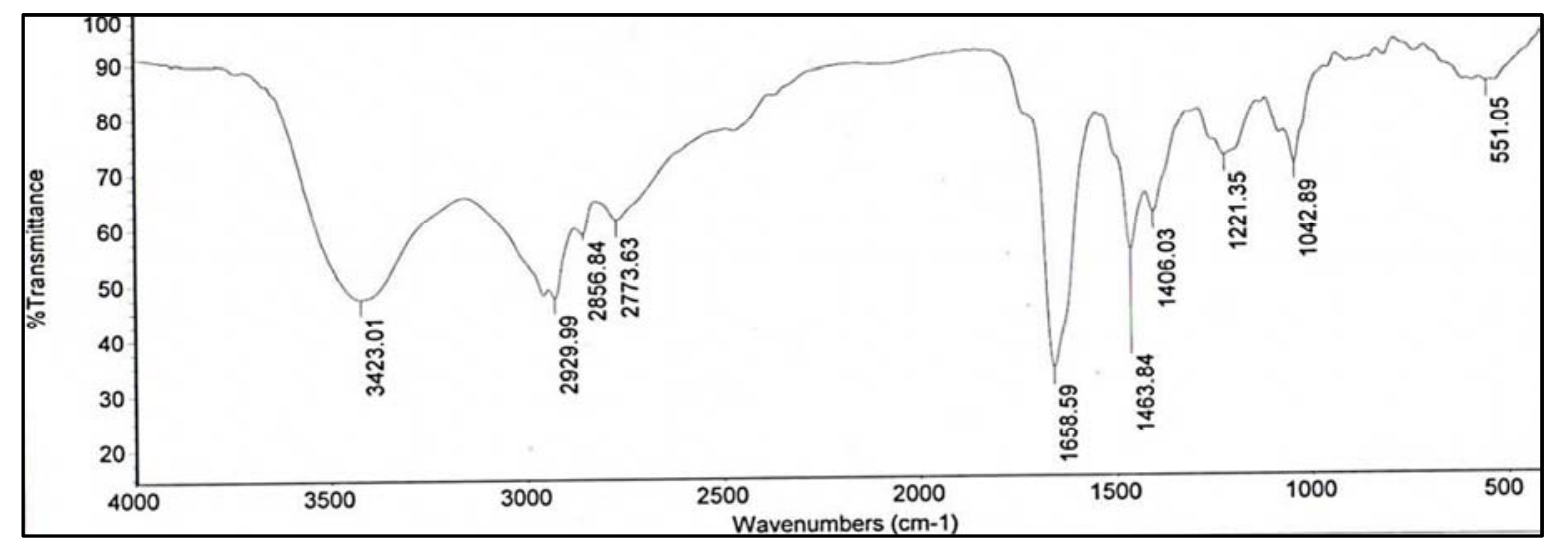

Figure 3. FTIR spectra of cationic polyurethane surfactants (PQ14). 


\subsection{2. ${ }^{1}$ H-NMR Spectroscopic Analysis}

The $\mathrm{H}^{1} \mathrm{NMR}$ spectra of the synthesized cationic surfactants (Figure 4 for PQ14 as representative for the prepared surfactants) showed the appearance of signals at: $\delta=0.85$ ppm (t, $3 \mathrm{H}, \mathrm{CH}_{3}$ ) assigned to terminal methyl group; 1.25 ppm (m, nH, $\left.\mathrm{CH}_{2}\right)$ attributed to the methylene groups of the fatty chains; $2.5 \mathrm{ppm}\left(\mathrm{t}, 3 \mathrm{H}, \mathrm{CH}_{3} \mathrm{Ph}\right)$ assigned to methyl group of toluene diisocyanate moiety; $7.8 \mathrm{ppm}, 8.0 \mathrm{ppm}$ and $8.2 \mathrm{ppm}$ ( $\mathrm{m}, 4 \mathrm{H}$, phenyl group).

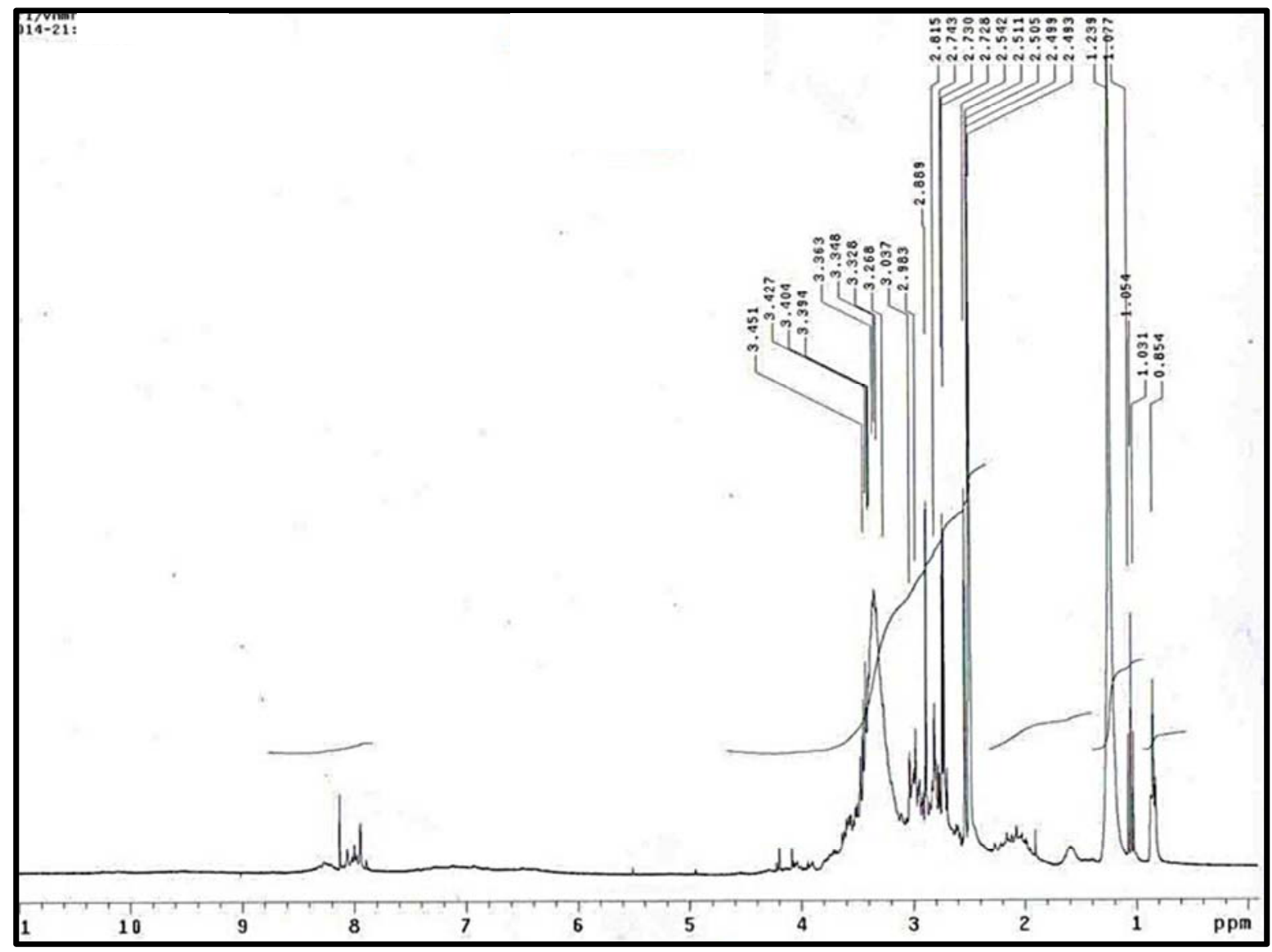

Figure 4. 1H-NMR spectra of PQ14 surfactant.

\subsubsection{Molecular Weight Measurements}

The molecular weights of the prepared cationic surfactants were determined using GPC chromatographic measurements according to the methodology of our colleague [16]. The results showed that the surfactant molecules contain an average of 18 repeated units (exactly 17.8 units). The obtained values of the molecular weights of the different surfactants were listed in Table 1.

\subsubsection{UV-Vis Spectroscopy}

UV-Vis absorption spectra were used to determine the formation of copper and nickel nanoparticles stabilized by different cationic Thiol polyurethane surfactants. UV-Vis absorption spectra of the prepared Copper and Nickel nanoparticles stabilized by different cationic Thiol polyurethane surfactants were recorded in water as a solvent in order to monitor their formation and stability (Figures 5 and 6). Cationic Thiol polyurethane surfactants with Copper and Nickel nanoparticles were confirmed by the appearance of new bands in UV spectra. UV-Vis spectroscopy is quite sensitive to the formation of copper and nickel nanoparticles due to surface Plasmon excitation.

UV spectrum of Copper nanoparticles for characterizing the metallic nature whose broad peak corresponds to the $\mathrm{Cu}$ range from $350-550 \mathrm{~nm}$.

UV spectrum of Nickel nanoparticles for characterizing the metallic nature whose broad peak corresponds to the $\mathrm{Ni}$ range from $250-370 \mathrm{~nm}$.

Figures 5 and 6 shows absorption spectra of $\mathrm{Cu}$ NPs and Ni NPs capped by prepared cationic surfactants, which show absorption band listed in table 2 which an indication on formation Copper and Nickel nanoparticles, due to surface Plasmon resonance of Copper and Nickel nanoparticles. Bands at $\lambda$ max range from 210 to $314 \mathrm{~nm}$ characteristic for the used capping agents, which matches with the band, appeared for aqueous solution of the used capping agents alone. It is known that the amount and size of Copper and Nickel nanoparticles are positively related with the adsorption peak intensity and the $\lambda \max$ on the UV-Vis spectra respectively. 


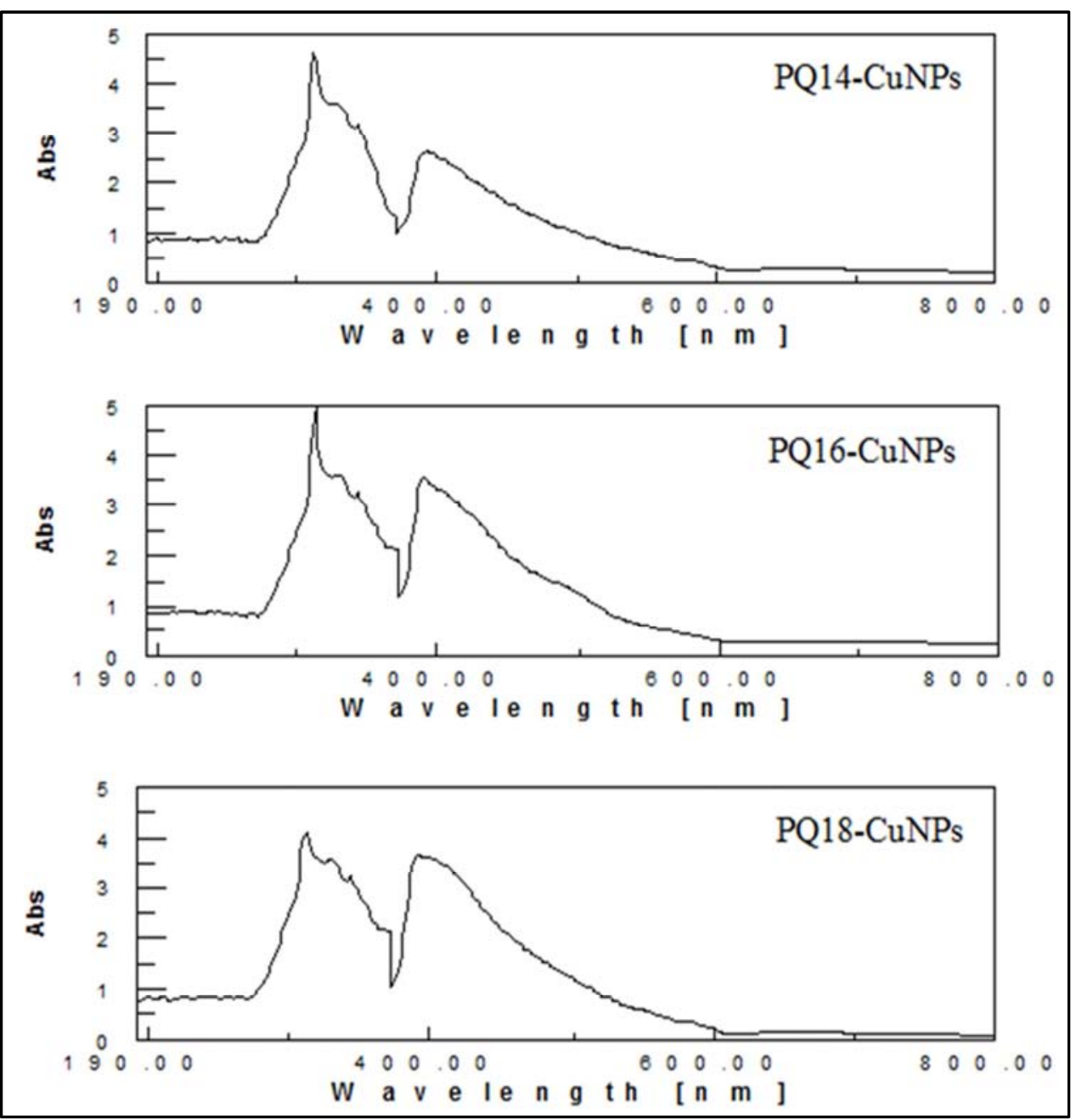

Figure 5. UV spectra of compounds (PQ14-CuNPs, PQ16-CuNPs and PQ18-CuNPs).

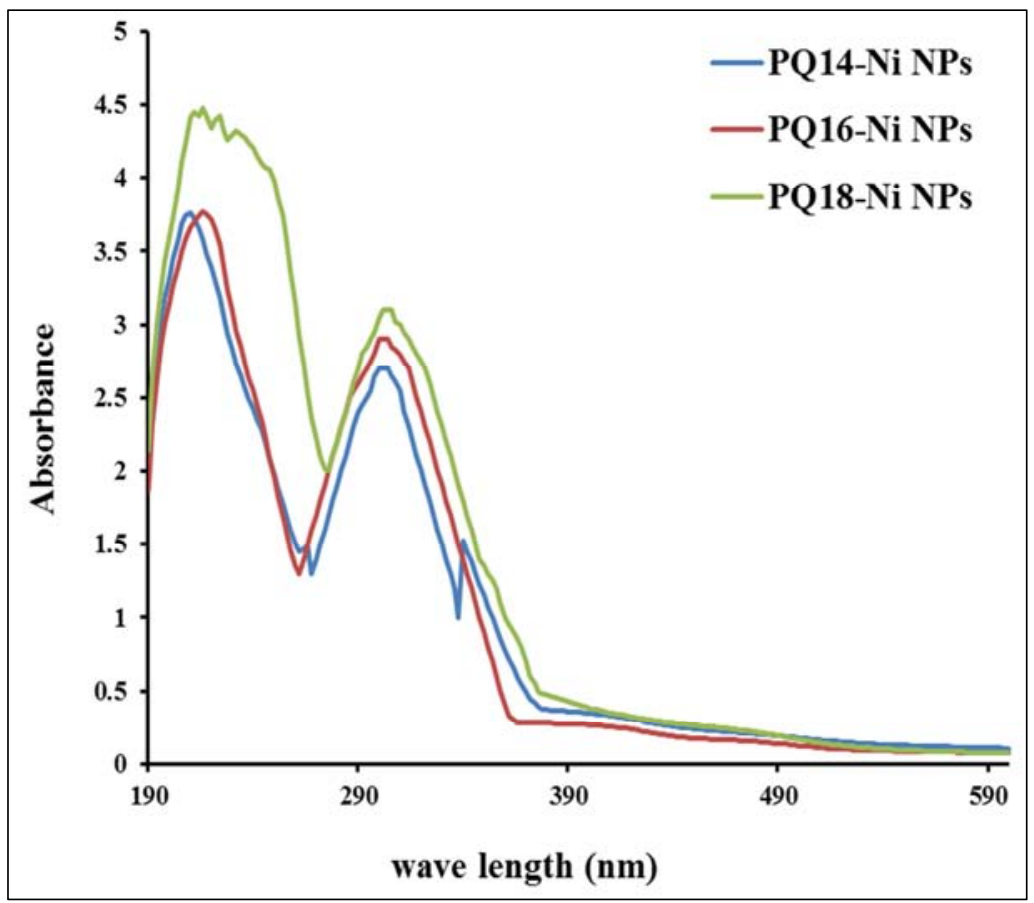

Figure 6. UV spectra of compounds (PQ14-NiNPs, PQ16-NiNPs and PQ18-NiNPs). 
Table 2. UV absorption maxima of Copper and Nickel nanoparticles with Cationic Thiol polyurethane surfactants.

\begin{tabular}{ll}
\hline Compounds & $\boldsymbol{\lambda}_{\max }(\mathbf{n m})$ \\
\hline PQ14-Cu NPs & 311,390 \\
PQ16- Cu NPs & 311,400 \\
PQ18- Cu NPs & 309,402 \\
PQ14-Ni NPs & 212,310 \\
PQ16- Ni NPs & 220,298 \\
PQ18- Ni NPs & 218,308 \\
\hline
\end{tabular}

\subsubsection{TEM Spectroscopy}

TEM spectroscopy determines the size and morphology of the formed nanoparticles. The size and morphology of the prepared Copper and Nickel nanoparticles stabilized by cationic Thiol polyurethane surfactants were investigated using transmission electron microscope (TEM). It is clear from TEM images (Figures 7 and 8) that the Copper and Nickel nanoparticles stabilized by cationic Thiol polyurethane surfactants are predominantly spherical in shape and polydispersed. The TEM image showed the selfassembling of the prepared surfactant on the Copper and Nickel nanoparticles which causes the stabilization of the Nano size of these nanoparticles due to the formation of Nano shells with the used surfactant.

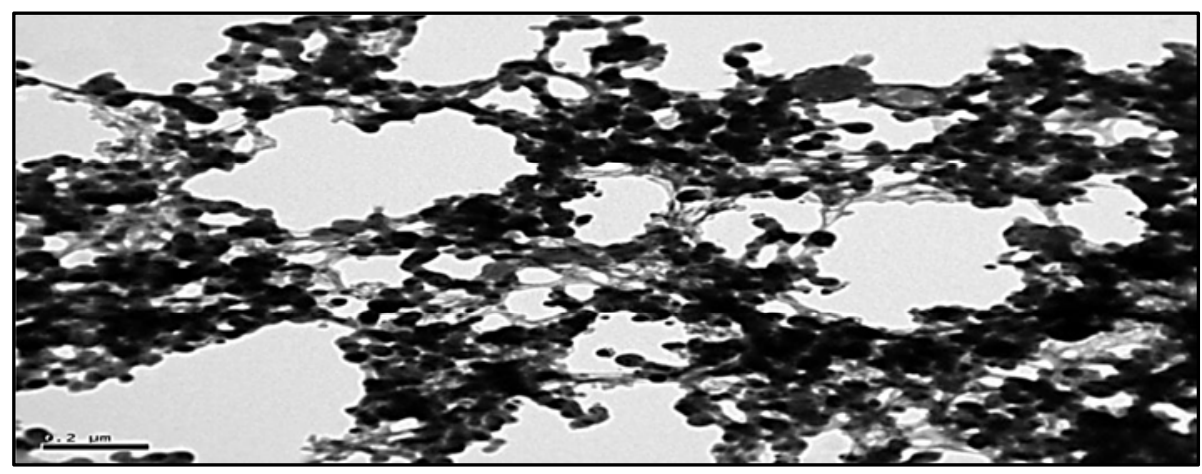

Figure 7. TEM image of $P Q 14-C U N P$ s.

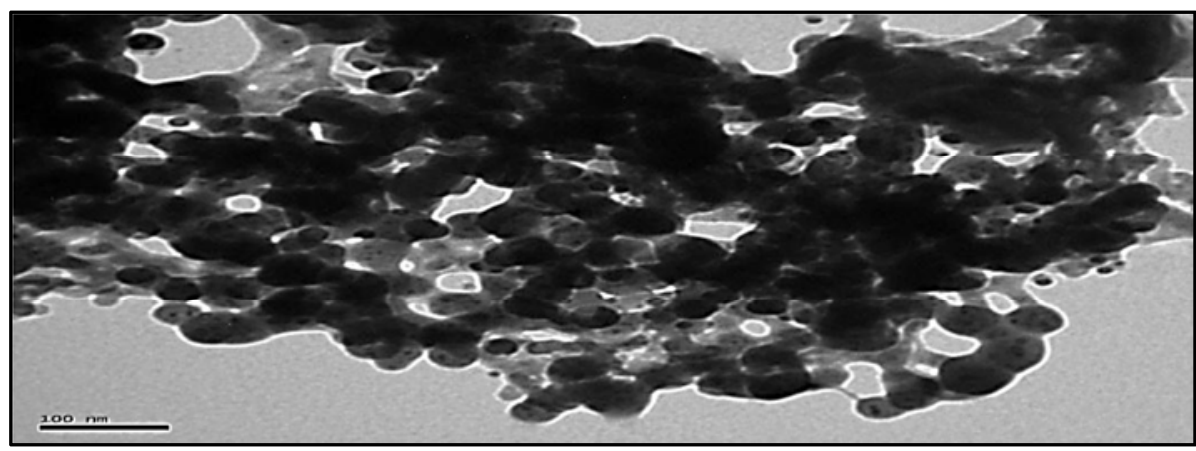

Figure 8. TEM image of $P Q 14-N i N P S$.

\subsection{Surface Activity}

\subsubsection{Surface Tension ( $y$ ) and Critical Micelle Concentration (CMC)}

Surface tension is a characteristic property of aqueous medium due to the presence of hydrogen bonds between water molecules. This property is strongly influenced by the presence of adsorbed molecules at the air-aqueous phase interface. The surface tension value of the bi-distilled water at $25^{\circ} \mathrm{C}$ was reported as $71.8 \mathrm{mN} / \mathrm{m}$.

Figures 9 and 10 represents the variation of the surface tension of the prepared Nano cationic polyurethane surfactants in their solutions at different concentrations at $25^{\circ} \mathrm{C}$. Obviously, surface tension-concentration profiles of the prepared Nano cationic surfactants represented two characterized sections; the first at comparatively low concentration values that is highly responsive for the change in the surfactant concentration (pre-micellar region); while the second at comparatively higher concentrations which characterized by almost stable surface tension values (postmicellar region). Extrapolation of the two concentration regions determines the concentration of the micelles formation (CMC) [17, 18]. As well, the surface tension profiles of the prepared surfactants were used to calculate their surface parameters in their solutions and were listed in Table 3.

The surface tension values of the prepared surfactants solutions are considerably lower than conventional polymeric surfactants [17]. That can be attributed to the cationic and Nano metals nature of the prepared surfactants. The calculated critical micelle concentration values of the prepared Nano cationic polyurethane surfactants are ranged between $50 \times 10^{-6}$ and $19.9 \times 10^{-6} \mathrm{M}$ at $25^{\circ} \mathrm{C}$. Generally, the critical micelle concentration values are gradually decreased by increasing the hydrophobic chain lengths of the different surfactant molecules. 


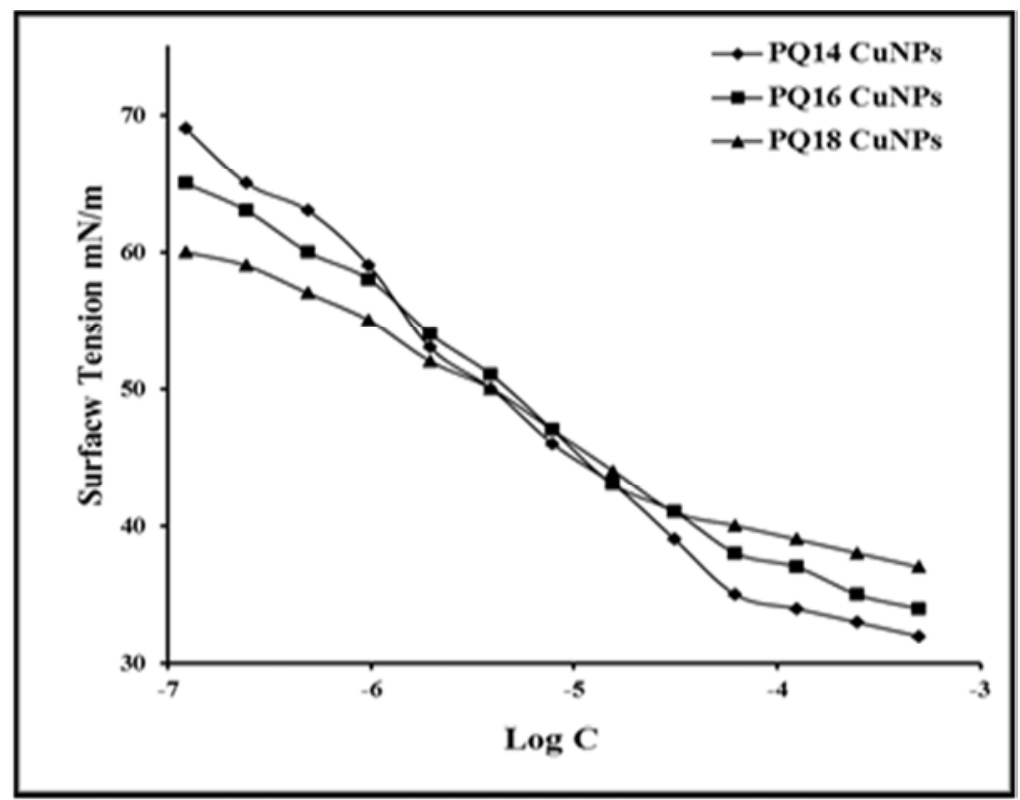

Figure 9. Surface tension vs. log concentration profile of the synthesized cationic Thiol polyurethane CuNp surfactants (PQ14-CuNPs, PQ16-CuNPs and $P Q 18-C u N P s)$ at $25^{\circ} \mathrm{C}$.

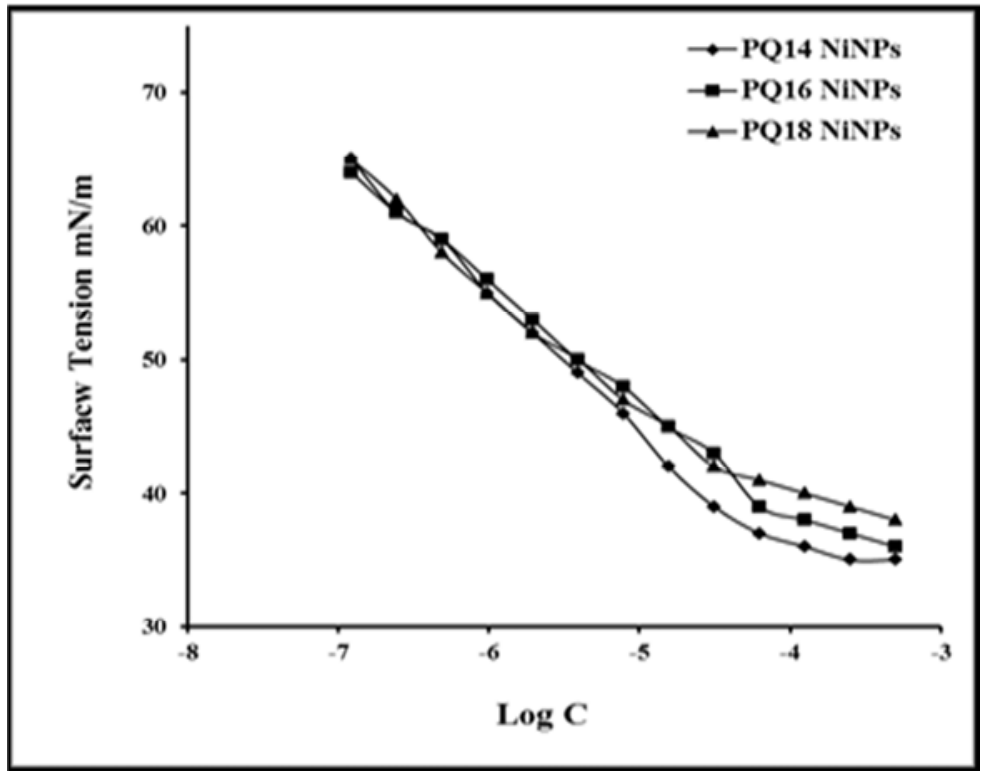

Figure 10. Surface tension vs. log concentration profile of the synthesized cationic Thiol polyurethane NiNp surfactants (PQ14- NiNPS, PQ16- NiNPs and $P Q 18$ - NiNPs) at $25^{\circ} \mathrm{C}$.

\subsubsection{Effectiveness $\left(\pi_{C M C}\right)$ and Efficiency $\left(P_{20}\right)$}

The effectiveness values identify the difference between the apparent surface tension of the bi-distilled water $\left(\gamma_{0}\right)$ and that of the surfactant solution at the critical micelle concentration $\left(\gamma_{\mathrm{CMC}}\right)$, and can be calculated using Equation 1 [19]:

$$
\pi_{\mathrm{CMC}}=\gamma_{\mathrm{o}}-\gamma_{\mathrm{CMC}}
$$

$\pi_{\mathrm{CMC}}$ values of the prepared Nano cationic surfactants were calculated and listed in Table 3. It is clear that the gradual increase in the hydrophobic chain length increases the effectiveness values of the surfactant solutions. That can be attributed to the gradual decrease in the surface tension of the different surfactant solutions at their CMC values $\left(\gamma_{\mathrm{CMC}}\right)$ [20].

The efficiency $\left(\mathrm{PC}_{20}\right)$ is defined as the surfactant concentration which comprises $20 \mathrm{mN} / \mathrm{m}$ depressions in the surface tension of the surfactant solution compared to the bidistilled water, i.e., the surfactant concentration which has $52.1 \mathrm{mN} / \mathrm{m}$ at $25^{\circ} \mathrm{C}$ [21]. This value is useful in comparing between the different surfactant series. It is clear from data in Table 3 that the gradual increase in the hydrophobic chain length is gradually increasing the efficiency of the prepared surfactants. 
Table 3. Surface properties of the synthesized cationic polyurethane surfactants at $25^{\circ} \mathrm{C}$.

\begin{tabular}{|c|c|c|c|c|c|c|}
\hline Compound & CMC, Mole/L $\left(\mathrm{x10}^{-6}\right)$ & $\gamma_{\mathrm{cmc}}, \mathbf{m N} / \mathbf{m}$ & $\pi_{\mathrm{cmc}}, \mathbf{m N} / \mathbf{m}$ & $\Gamma_{\max }, \mathrm{X10}{ }^{-11}$ Mol. $\mathrm{K}^{-1} \mathrm{~cm}^{-1}$ & $\mathbf{A}_{\min }, \mathbf{n m}^{2}$ & $\mathrm{Pc}_{20}$, Mole/L (x 10 $\left.{ }^{-6}\right)$ \\
\hline PQ14-Cu NPs & 50 & 35 & 36.8 & 19.3 & 8.6 & 2.82 \\
\hline PQ16-Cu NPs & 40 & 39 & 32.8 & 16.3 & 10.1 & 2.13 \\
\hline PQ18-Cu NPs & 32 & 41 & 30.8 & 12.4 & 13.4 & 1.82 \\
\hline PQ14- Ni NPs & 39 & 37 & 34.8 & 15.6 & 10.6 & 0.79 \\
\hline PQ16- Ni NPs & 31 & 40 & 31.8 & 14.3 & 11.6 & 1.99 \\
\hline PQ18- Ni NPs & 19.9 & 42.5 & 29.3 & 13.3 & 12.5 & 1.95 \\
\hline
\end{tabular}

\subsubsection{Maximum Surface Excess $\left(\Gamma_{\max }\right)$ and Minimum Surface Area $\left(A_{\min }\right)$}

The maximum surface excess $\left(\Gamma_{\max }\right)$ values are defined as the concentration of the surface active agent molecules at the air-water interface at the complete coverage of surface, i.e., at saturation [22]. The maximum surface excess values $\left(\Gamma_{\max }\right)$ of the prepared cationic polyurethane surfactants in their aqueous solutions were calculated at $25^{\circ} \mathrm{C}$ according to Equation 2 and listed in Table 3.

$$
\Gamma_{\max }=[(\partial \gamma / \partial \log C)] /[2.303 R T]
$$

Where, $\partial \gamma / \partial \log C$ : slope of pre-micellar region in surface tension-log $\mathrm{C}$ profile, $\mathrm{R}$ : universal constant of gases, $\mathrm{T}$ : absolute temperature.

The values of $(\partial \gamma / \partial \log C)$ are the slopes of the pre-micellar region of the surface tension profile and also called the surface pressure. The surface pressure of the surfactant in its solution represents the movement of the surfactant molecules upward the interface due to the hydrophobic effect of the surfactant molecules in the aqueous phase. The hydrophobic effect is expressed for the process where nonpolar groups (hydrophobe) in surfactant molecules are moved spontaneously to the water interface. The presence of the hydrophobes in the aqueous phase leads to formation of cavities in the water phase to host these hydrophobe. This leads to decrease the solubility of the hydrophobes in the water phase, and also the corresponding CMC values; in addition to increase the adsorption of surfactant molecules at the interface [23]. It is clear from Table 3 that the maximum surface excess $\left(\Gamma_{\max }\right)$ values are gradually decreased by increasing the hydrophobic chain length of the surfactant molecules.

The maximum surface excess values are used to determine the average area occupied by the adsorbed surfactant molecules $\left(\mathrm{A}_{\text {min }}\right)$ at air/water interface (in $\mathrm{A}^{2}$ unit) based on Equation 3 [24]:

$$
\mathrm{A}_{\min }=10^{20} /\left[\Gamma_{\max } \cdot \mathrm{N}_{\mathrm{av}}\right]
$$

$\mathrm{N}_{\mathrm{av}}$ : Avogadro's number $\left(6.023 \times 10^{23}\right.$ molecule/mole $)$.

It is clear from Table 3 that the average area occupied by the prepared cationic surfactants at the interface is gradually increased by the gradual increase in the hydrophobic chains.

The surface activity of the prepared surfactants and their comparable high adsorption tendencies at the interface and also their compactness at this interface by increasing their hydrophobic chain length are considered important features in the surfactant solution and favored properties during their application [24] as effective corrosion inhibitors for metals in corrosive media and biocides against microorganisms.

\subsubsection{Interfacial Tension and Emulsification Efficiency of the Synthesized (Copper and Nickel Nanoparticles) \\ Stabilized by Cationic Thiol Polyurethane Surfactants}

Interfacial tension (IT) values of the synthesized nano cationic Thiol polyurethane surfactants were measured between their aqueous solutions and paraffin oil at $25^{\circ} \mathrm{C}$ (table 4).

The emulsification efficiency in this study was measured as the time required for separation of $9 \mathrm{ml}$ of pure water from the emulsion formed between $10 \mathrm{ml}$ of surfactant solution of the synthesized cationic Thiol polyurethane surfactants and $10 \mathrm{ml}$ of paraffin oil. Increasing the time required for separation of the desired amount of water from the emulsification system indicates the stability of that emulsion.

From (table 4) It is clear that the Interfacial tension and emulsification efficiency of the synthesized surfactants decreases with increases the hydrophobic chain length.

\subsubsection{Thermodynamics of the Synthesized (Copper and Nickel Nanoparticles) Stabilized by Cationic Thiol Polyurethane Surfactants}

The standard free energy of micellization and adsorption of the synthesized cationic Thiol polyurethane surfactants and its free energy of their solution at $25^{\circ} \mathrm{C}$ can be calculated using the following thermodynamic equations: [25]

$$
\begin{gathered}
\Delta \mathrm{G}_{\text {mic }}=2.303 R T \log (\mathrm{CMC}) \\
\Delta \mathrm{G}_{\mathrm{ads}}=\Delta \mathrm{G}_{\mathrm{mic}}-\left(0.006 \times \pi_{\mathrm{cmc}} \times \mathrm{A}_{\text {min }}\right)
\end{gathered}
$$

Increasing the number of methylene groups in the hydrophobic chain length, increases its standard free energy of micellization [26].

From (table 4) it is clear that $\Delta \mathrm{G}_{\text {mic }}$ and $\Delta \mathrm{G}_{\mathrm{ads}}$ of values of all synthesized nano cationic Thiol polyurethane surfactants are negative. The negativity of this values indicates the spontaneous behavior of two process and this refer to the equilibrium between the two phases of the surfactant molecules (adsorbed and micellized phase) in their solutions at constant temperature $25^{\circ} \mathrm{C}$.

When the hydrophobic chain length of the synthesized nano cationic Thiol polyurethane surfactants increase, $\Delta \mathrm{G}_{\text {mic }}$ and $\Delta \mathrm{G}_{\mathrm{ads}}$ increases in. Also, the slightly increase of $\Delta \mathrm{G}_{\mathrm{ads}}$ values may be ascribed to the tendency of the molecules to adsorb at the air-water interface until complete surface coverage and also the slightly increase of $\Delta \mathrm{G}_{\text {mic }}$ values indicate to the tendency of the surfactant molecules to 
migrate to the bulk of solution to form micelle. And also the negativity values of $\Delta \mathrm{G}_{\mathrm{ads}}$ are greater than the corresponding $\Delta \mathrm{G}_{\text {mic }}$. This indicates that tendency of surfactant molecules to be adsorbed at the air-water interface rather than escape to the bulk of their solutions.

Table 4. Interfacial tension, Emulsification power and Thermodynamic properties of the synthesized nano cationic Thiol polyurethane surfactants at $25^{\circ} \mathrm{C}$.

\begin{tabular}{lllll}
\hline Compound & Interfacial tension, $\mathbf{~ m N} / \mathbf{m}$ & Emulsification power/ sec. & $\boldsymbol{\Delta G}_{\text {ads }}$ \\
\hline PQ14-Cu NPs & 10 & 15 & -7.6 & -8.3 \\
PQ16-Cu NPs & 12 & 20 & -5.9 \\
PQ18-Cu NPs & 15 & 34 & -9.4 & -6.0 \\
PQ14-Ni NPs & 12 & 14 & -8.4 & -8.9 \\
PQ16-Ni NPs & 16 & 19 & -6.1 \\
PQ18-Ni NPs & 18 & 30 & -6.0 \\
\hline
\end{tabular}

\subsubsection{Antimicrobial Activity of the Synthesized Cationic Surfactants and Their Nanostructures}

The biological activities of the synthesized cationic surfactants (PQ14, PQ16 and PQ18) and their nanostructures with copper and nickel nanoparticles was screened against pathogenic Gram-positive (Bacillus subtilis and Staphylococcus aureus), Gram-negative (Salmonella typhimurium and Escherichia coli), bacteria and also, some pathogenic fungi (C. albicans and Asperigllus niger) using the values of the inhibition zone diameter tests and the results are summarized in Table 5. Data in Table 5 indicating that the synthesized compounds have antimicrobial activity rang from a moderate to slight high effect on Gram negative bacteria and Gram positive bacteria and moderate effect on fungi and high effect on yeast compared to the drug reference used.

The biological activities of surfactants often show a nonlinear dependence on their chain length, where bactericides and fungicide activity increase by increasing hydrophobic chain length.

Table 5. Antimicrobial activity of synthesized surfactants against pathogenic bacteria, yeast and fungi.

\begin{tabular}{|c|c|c|c|c|c|c|}
\hline \multirow{3}{*}{ Compounds } & \multicolumn{4}{|l|}{ Bacteria } & \multirow{3}{*}{$\begin{array}{l}\text { Yeast } \\
\text { Candida albicans }\end{array}$} & \multirow{3}{*}{$\begin{array}{l}\text { Fungi } \\
\text { Aspergillus niger }\end{array}$} \\
\hline & \multicolumn{2}{|l|}{ Gram positive } & \multicolumn{2}{|l|}{ Gram negative } & & \\
\hline & Bacillus subtilis & Staphylococcus aureus & Salmonella typhimurium & Escherichia coli & & \\
\hline Control & 26 & 25 & 28 & 27 & 28 & 26 \\
\hline PQ14 & 23 & 14 & 0 & 10 & 17 & 0 \\
\hline PQ16 & 25 & 9 & 0 & 23 & 19 & 0 \\
\hline PQ18 & 22 & 0 & 0 & 21 & 27 & 0 \\
\hline PQ14-Cu NPs & 33 & 20 & 15 & 17 & 26 & 14 \\
\hline PQ18-Cu NPs & 13 & 33 & 15 & 14 & 31 & 12 \\
\hline PQ14-Ni NPs & 28 & 19 & 12 & 15 & 22 & 11 \\
\hline PQ16-Ni NPs & 18 & 26 & 19 & 17 & 17 & 20 \\
\hline PQ18-Ni NPs & 11 & 24 & 12 & 22 & 18 & 17 \\
\hline
\end{tabular}

It is clear that the antimicrobial activities are gradually increased by increasing the hydrophobic chain length. The PQ18 surfactant showed the maximum antimicrobial activities against the tested bacterial strains. That behavior is depending on the surface activities of these biocides. Increasing the hydrophobic chain length increases the adsorption tendency of the biocide molecules at the various surfaces (water or microorganism's membranes). Hence, the potent action of the molecules is increased due to their high population at the cellular membrane $[27,28]$.

General observation for data in Table 5 indicates that the Gram- positive bacteria are more resistant to the tested compounds compared with the Gram-negative bacteria. The data provided from the inhibition zone diameter are describing the general behavior of the tested biocides against the different bacterial genera. The results of the antifungal activity obtained from the biological study showed promising features of the tested biocides against the most pathogenic fungal strain (C. albicans).

By inspection data in Table 5, the biological activity of copper nanoparticle stabilized by synthesized cationic Thiol polyurethane surfactants higher than corresponding synthesized cationic Thiol polyurethane surfactants, this can be attributed to copper and nickel nanoparticle alone has biological activity, so prepared surfactant capped copper and nickel nanoparticles have higher activity, this can be attributed to the higher surface area of prepared nanoparticles and the acquired positive charge of prepared copper and nickel nanoparticles in addition positive charge of cationic surfactants, where these positive charge facilitate adsorption at negative cell wall membrane of bacteria. In addition to the bactericidal effect of metal nanoparticles has been attributed to their small size and high surface to volume ratio, which allows them to interact closely with microbial membranes and is not merely due to the release of metal ions in solution. A cell wall is present around the outside of the bacterial cell membrane and it is essential to the survival of bacteria.

\section{Conclusion}

In this study, Novel polymeric Thiol polyurethane cationic surfactants were prepared and characterized using different 
spectroscopic tools. The results of the study showed the acceptable surface activities of these surfactants including critical micelle concentration, effectiveness, and efficiency. The maximum surface excess values showed their high tendency towards adsorption at the interface. Average surface area of the surfactant molecules at the interface showed their dense arrangement at the interface, which can be applied in several industrial applications.

The synthesized cationic Thiol polyurethane surfactants and their nanoparticles were tested against different strain of bacteria using inhibition zone diameters and showed good antimicrobial activities against the tested microorganisms. Antibacterial activity of the parent cationic Thiol polyurethane surfactants exhibited high efficiency against the tested microorganisms compared to the drug reference used. The antibacterial activity of the synthesized compounds can be referred to several factors including chemical structure factors and surface factors. The antibacterial activities are gradually increased by increasing the hydrophobic chain length of the synthesized compounds. That behavior is depending on the surface activities of these biocides. Increasing the hydrophobic chain length increases the adsorption tendency of the biocide molecules at the various surfaces (water or microorganism's membranes). Hence, the potent action of the molecules is increased due to their high population at the cellular membrane. Copper and Nickel nanoparticles capped by cationic Thiol polyurethane surfactants have higher antibacterial and antifungal activity than the parent cationic surfactants; this can be attributed to the higher surface area of prepared nanoparticles and their small size and high surface to volume ratio. In addition copper and nickel nanoparticles alone have biological activity.

\section{References}

[1] Akita S, Akino K, Imaizumi T, Tanaka K, Anraku K, Yano H, Hirano A, (2006) A polyurethane dressing is beneficial for split-thickness skin-graft donor wound healing. Burns 32:447451.

[2] Ismail EA, Motawie AM, Sadek EM, (2011) Synthesis and characterization of polyurethane coatings based on soybean oil-polyester polyols Egypt J Petrol 20:1-8.

[3] Mekewi MA, Ramadan AM, El Darse FM, Abdel Rehim MH, Mosa NA, Ibrahim MA (2017) Preparation and characterization of polyurethane plasticizer for flexible packaging applications: Natural oils affirmed access. Egypt $\mathbf{J}$ Petrol 26:9-15.

[4] Radhakrishnan B, Cloutet E, Cramail H, (2002) Synthesis of uniform polyurethane particles by step growth polymerization in a dispersed medium, Colloid Polym Sci 280: 1122-1130.

[5] Randall D, Lee S, The Polyurethane Book, Wiley (ISBN: 9780-470-85041-1) (2003).

[6] Lapprand A, Boisson F, Delolme F, Méchin F, Pascault JP (2005) Reactivity of isocyanates with urethanes: Conditions for allophanate formation, Polym Degrad Stab 90:363-373.
[7] Fisicaro E, Biemmi M, Compari C, Duce E, (2007) Thermodynamic properties of aqueous micellar solutions of some new acetylated gluco-cationic surfactants. Colloids Surf A 301:129-136

[8] Negm NA, Mohamed AS, (2008) Synthesis, characterization and biological activity of sugar-based gemini cationic amphiphiles. J Surfact Deterg 11:215-221.

[9] Shokry SA, El Morsi AK, Sabaa MS, Mohamed RR, El Sorogy HE (2015) Synthesis and characterization of polyurethane based on hydroxyl terminated polybutadiene and reinforced by carbon nanotubes. Egypt J Petrol 24:145-54.

[10] Negm NA, Morsy SMI, (2005) Corrosion inhibition of triethanol ammonium bromide mono-and dibenzoate as cationic inhibitors in an acidic medium. J Surfact Deterg 8:283-287.

[11] Zaki MF, Badawi AM, Sabbah IA, Abdelghani RA, Hendawy ME, (2015) Synthesis, Characterization and Surface Activities of Cationic Polysaccharide (Aloe) Schiff Base Surfactants. J Surfact Deterg 18:455-461.

[12] Negm NA, El Hashash MA, Youssif MA, Ismail EA, Abdeen ZI, Abdel Rahman NR, (2017) Novel Nonionic Polyurethane Surfactants and $\mathrm{Ag}$ Nanohybrids: Influence of Nonionic Polymeric Chains. J Surfact Deterg 20:173-182.

[13] Saleh N, Khowdiary M, Badawi AM, (2014), Synthesis and Antitumor and Surface Activity of Novel Tetrachloro Metallate Complexes of Sulfaquinoxaline with $\mathrm{Co}$ (II), $\mathrm{Cu}$ (II), or Sn (II) Chlorides, Tenside Surf. Det. 51: 4-15.

[14] Sara Busi , Manu Lahtinen, Jussi Valkonen, Kari Rissanen, (2006), Crystal structures and thermal behavior of bis [dibenzyldimethylammonium] $\mathrm{CuBr} 4, \quad$ bis [dibenzyldimethylammonium] $\mathrm{CuCl} 4$ and bis [dimethyldi (2 phenylethyl) ammonium] $\mathrm{CuBr} 4$ crystallized from acetonitrile and dilute $\mathrm{HX}(\mathrm{XZCl}$ or $\mathrm{Br})$ solutions, Journal of Molecular Structure 794: 277-287.

[15] Negm NA, Abd-Elaal AA, Mohamed DE, El-Farargy AF, Mohamed S, (2015) Synthesis and evaluation of silver nanoparticles loaded with Gemini surfactants: surface and antimicrobial activity. J Ind Eng Chem.; 24:34-41.

[16] Azzam EMS, El-Frarrge AFM, Ismail DA, Abd-Elaal AA, (2011) Enhancement of the surface activity for some monomeric and polymeric thiol surfactants using silver nanoparticles. J Disp Sci Technol 32:816-22.

[17] Negm NA, Zaki MF, Salem MAI, (2010) Synthesis and evaluation of 4-diethyl amino benzaldehyde Schiff base cationic amphiphiles as corrosion inhibitors for carbon steel in different acidic media. J Disp Sci Technol 12:321-329.

[18] Hafiz AA, Badawi AM, El-Deeb FI, Soliman EA, El-Awady MY, (2010) Ferrocene-based cationic surfactants: surface and antimicrobial properties. J Surfact Deterg 13:165-172.

[19] Negm NA, El-Farargy AF, Tawfik SM, Abdelnour AM, Hefni HH (2013) Synthesis, surface and thermodynamic properties of substituted poly triethanolamine nonionic surfactants. J Surfact Deterg 16:333-342.

[20] Negm NA, Tawfik SM, Badr EA, Abdou MI, Ghuiba FM, (2015) Evaluation of some nonionic surfactants derived from vanillin as corrosion inhibitors for carbon steel during drilling processes. J Surfact Deterg 18:413-419. 
[21] Migahed MA, Negm NA, Shaban MM, Ali TA, Fadda AA, (2016) Synthesis, Characterization, Surface and Biological Activity of Diquaternary Cationic Surfactants Containing Ester Linkage. J Surfact Deterg 19:119-128.

[22] El-Sukkary MMA, Ghuiba FM, Sayed GH, Abdou MI, Badr EA, Tawfik SM, Negm NA, (2014) Evaluation of some vanillin-modified polyoxyethylene surfactants as additives for water based mud. Egypt J Petrol 23:7-14.

[23] Kronberg B, Castas M, Silvestonti R, (1994) Understanding the hydrophobic effect. J Disp Sci Technol 15:333-351.

[24] Kuperkar K, Modi J, Patel K, (2012) Surface-active properties and antimicrobial study of conventional cationic and synthesized symmetrical Gemini surfactants. J Surfact Deterg 15:107-115.

\section{Biography}

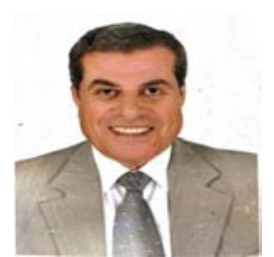

Ibrahim Abdelsalam Sabbah is a professor of organic chemistry, Chemistry department, Faculty of Science Al-Azhar University, Cairo, Egypt. His interests are focused on synthesis and evaluation of organic and organometallic compounds

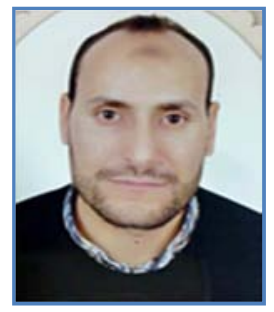

Mostafa Eid Hendawy is a Ph.D. student working as a chemist in the Foam Factory. His interests are in synthesis and applications of environmentally friendly compounds and their uses as biocides.
[25] Negm NA, Salem MAI, Badawi AM, Zaki MF, (2003) Synthesis, surface and thermodynamic properties of some novel methyl diethanol ammonium bromide as cationic surfactants. Ain Shams Sci Bull 41:1-13.

[26] Negm NA, Mohamed AA, El-Awady MY, (2004) Influence of structure on the cationic polytriethanol ammonium bromide derivatives. I. Synthesis, surface and thermodynamic properties. Egypt J Chem 47:369-381.

[27] Cukurovali A, Yilmaz I, Gur S, Kazaz C, (2006), Synthesis, antibacterial and antifungal activity of some new thiazolylhydrazone derivatives containing 3-substituted cyclobutane ring. Eur. J. Med. Chem. 41: 201-207.

[28] Negm NA, Morsy SMI, Said MM, (2005), Biocidal activity of some Mannich base cationic derivatives. Bioorg. Med. Chem. 13: 5921-5926.

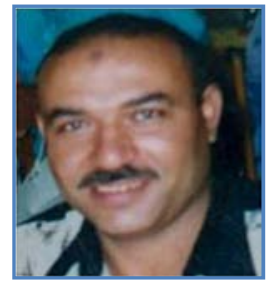

Mohamad Fahmy Zaky is a professor in the Petrochemicals Department of the Egyptian Petroleum Research Institute. $\mathrm{He}$ received his Ph.D. for a thesis in the field of surfactant applications from Ain Shams University, Cairo, Egypt in 2005. He is interested in surfactants applications, mainly corrosion and biological activity.

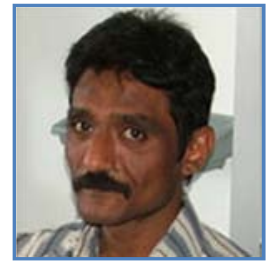

Nabel Abdelmonem Negm is a professor of applied petrochemicals in Petrochemicals Department, Egyptian Petroleum Research Institute. Now, he is an associate editor in Journal of surfactants and detergents, AOCS (JSD). He received his $\mathrm{PhD}$ from Ain Shams University in 2000. Currently, he is a vice-head of Petrochemicals Department, Egyptian Petroleum Research Institute, EGYPT. 